BMJ Open

Sport \&

Exercise

Medicine

\title{
Incidence of recreational sports-related sudden cardiac arrest in participants over age 12 in a general African population
}

Gladys M K Tchanana, ${ }^{1}$ Marcus Ngantcha, ${ }^{2}$ Matthew F Yuyun, ${ }^{3}$ Olujimi A Ajijola, ${ }^{4}$ Samuel Mbouh, ${ }^{5}$ Steve C T Tchameni, ${ }^{1}$ Ahmed Suliman, ${ }^{6}$ Aimé Bonny (D) ${ }^{7,8}$

\section{ABSTRACT}

Background The incidence of sports-related sudden cardiac arrest (SrSCA) in sub-Saharan Africa is unknown. Objective To determine the incidence of sudden cardiac arrest (SCA) in non-competitive athletes in an urban population of Cameroon, a country in sub-Saharan Africa. Methods Two study populations in Cameroon were used. A 12-month, multisource surveillance system of 86189 inhabitants over 12 years old recorded all deaths in two administrative districts of Douala City. All fields of sports, emergency medical service, local medical examiners and district hospital mortuaries were surveyed. Two blinded cardiologists used a verbal autopsy protocol to determine the cause of death. SCA was identified for all deaths occurring within 1 hour of onset of symptoms. A crosssectional study was conducted among 793 persons in Yaoundé City, which is the second study population aimed at determining the proportion of people who are physically active.

Results The mean age in the cross-sectional study was $27.3 \pm 10.7$, with more men $(56.2 \%)$. The cross-sectional study showed that $69.0 \%$ (95\% Cl 65.8 to 72.2$)$ of the population could be considered to have at least 3 hours of physical activity per week. The surveillance found that among 288 all-cause deaths, 27 (9.4\%) were due to SCA. One SrSCA was registered in a 35-year-old woman while running. Merging both sources revealed an SrSCA incidence of 1.7 (95\% Cl 0.2 to 12.0) cases per 100000 athletes per year.

Conclusion This pioneer study reports the incidence estimates of SrSCA in a sub-Saharan African general population and should be regarded as a first step to a big problem.

\section{INTRODUCTION}

Sudden cardiac death (SCD) remains a major public health problem claiming up to $20 \%$ of deaths in Western societies. ${ }^{12}$ Sudden cardiac arrest (SCA) is the leading medical cause of death in athletes. ${ }^{3}$ The incidence of sportsrelated sudden cardiac arrest (SrSCA) in several studies has ranged from 0.13 to 13.0 per 100000 person-years (PY) depending on the methodology, accuracy and population

\section{What are the new findings}

- The prevalence of physical activity (at least 3 hours of physical activity per week) in a general population in sub-Saharan Africa was established at 69.0\% (95\% Cl 65.8 to 72.2 ).

- This study is the first to provide an estimate of sports-related sudden cardiac arrest in a general population in a sub-Saharan country.

- With an incidence estimate of $1.7(95 \% \mathrm{Cl} 0.2$ to 12.0) cases per 100000 population, cardiac arrest during practice of recreational sports in Africa seems to be comparable with the rate in some Western countries.

studied, according to a meta-analysis of 21 studies with 1994 SrSCA over 437156081 $\mathrm{PY}^{4}$ Several studies around the world have estimated the incidence and causes of SrSCA in the populace of non-professional athletes. ${ }^{4}$ These data indicate that exercise is a precipitant factor of SCA. Indeed, the study reported the incidence of SrSCA was $0.72(95 \%$ CI 0.58 to 0.86 ) per $100000 \mathrm{PY}^{4}$ However, such data are scarce in Africa. To our knowledge, mortality during exercise was prospectively reported in Africa only in one study from Tunisia. ${ }^{5}$ The increased incidence of SrSCA in black athletes has been recorded in several studies. ${ }^{6}$ SrSCA is a catastrophic event with profound psychological impact on family and society. However, from a public health point of view, promoting exercise in the community brings substantial improvement to overall health, especially non-communicable diseases. While it is recognised that hypertrophic cardiomyopathy (HCM), for example, is a leading cause of SCA in professional athletes of African background, such data are limited in non-professional athletes. This is particularly useful, as such information would be useful for public health officials to accurately gauge utilisation and distribution of 
resources, such as automated external defibrillators, in public recreational areas. Therefore, we sought to investigate and establish the burden of recreational SrSCA in an urban sub-Saharan African population in Cameroon.

The secondary objective was to determine the number of people engaging in physical activity on a regular basis for at least 3 hours, defined in this study as recreational athletes. Information on the incidence of SCA among athletes will help to tailor some public health policies towards this specific group to prevent the occurrence of this event. The need to address basic preventative setting, such as mandatory preparticipation screening programmes, for athletes could be supported by establishing the first incidence rate in sub-Saharan Africa.

\section{METHODS}

\section{Study population}

Definition of concepts

$S C A$ is ascertained if an unexpected death happened without obvious extracardiac cause, occurring with a rapid witnessed collapse, or if unwitnessed occurring within 1 hour after onset of symptoms. A probable $S C D$ is an unexpected death without obvious extracardiac cause, occurring within the previous 24 hours. ${ }^{8}$

SrSCA is an SCA occurring during exercise or within 1 hour after exertion. ${ }^{3}$

A competitive sports activity is defined as any intensive physical activity during an official competition, be it individual or collective, and involves substantial rewards depending on the performance and level of excellence of the athlete. ${ }^{9}$

Recreational sports activity is characterised as any sports activity practised more than 3 hours per week, whether on a regular basis or not and outside of a competition. ${ }^{10}$

A recreational (leisure) or non-competitive athlete is any person practising sports more than 3 hours per week on a regular basis for his well-being and/or his own pleasure and outside of a competition. ${ }^{10}$

\section{Study population}

The methodology to achieve the aims of this study required data collection from two general population samples drawn from the two largest cities in Cameroon, Douala and Yaoundé, with similar sociodemographics and which have the infrastructure to facilitate accurate data collection. Data from the Douala population provided information on the incidence of SCA, while data from the Yaoundé population provided the percentage of non-competitive athletes enduring $\geq 3$ hours per week of physical activity. This study was prepared and reported in accordance with the Strengthening the Reporting of Observational Studies in Epidemiology checklist. ${ }^{11}$

\section{Data collection}

The first source was the number of SCA in the general population and in non-competitive athletes obtained by conducting a prospective, multiple-source, communitybased cohort surveillance of all cases of sudden unexplained death in the city of Douala, Cameroon ${ }^{12}$ and establishing the incidence in the general population. ${ }^{12}$ Two health areas from two administrative districts in Douala were randomly chosen to monitor all-cause deaths during the period from January to December 2013. The 2013 census indicated that $57 \%$ of the Cameroonian population were over 15 years of age. ${ }^{12} \mathrm{~A}$ total of 86188 inhabitants were monitored for all-death occurrence.

During the 12-month surveillance period, every natural and unexpected death was recorded by the staff of the health committees known as the COSA (Comité de Santé) within the neighbourhoods as well as the personnel working in the hospital mortuary. All fields of sports, emergency medical service (EMS), local medical examiners and district hospital mortuaries were also surveyed. In addition, special attention was paid to all cases of deaths reported by residents in the health areas, the local press, radio, churches and other places or means. Deaths were coded based on the 10th Revision of the International Classification of Diseases. ${ }^{13}$ Circumstances of death were collected by a postgraduate medical fellow supervised by a general physician (GP) from the district hospital. Together with a cardiologist, the medical fellow and GP identified all cases of sudden natural death that possibly met the clinical definition of SCA. ${ }^{814}$ Cases of SCA were mainly ascertained by verbal autopsy from the household administrative office and the COSA,${ }^{15}$ district hospital mortuaries, public and private medical centres databases, as well as EMS and ambulance transportation service reports. In rare situations where data obtained from mortuaries revealed that patients had undergone autopsy from a pathologist (less than $1 \%$ ), the cause of death was noted. ${ }^{15}$ When a case of SCA was suspected, confirmation was required from a second cardiologist. If both cardiologists disagreed, a third experienced specialist was consulted. Data were collected using a questionnaire designed to meet the criteria for the verbal autopsy model. ${ }^{14}{ }^{15}$ Among victims of SCA belonging to the population of competitive athletes or highly active people, if the victim of SCA was known to be either a competitive or non-competitive athlete, the physical activity during the last 3 hours before death occurred was recorded. ${ }^{14}$

However, the definition of SrSCA used in the study was death or cardiac arrest that occurred during exercise or within 1 hour of cessation of sports activity. ${ }^{3}$ Figure 1 provides an overview of the flow of participants who experienced SCA.

The second source was a cross-sectional study conducted in Yaoundé, the capital of Cameroon. The sample of 1066 inhabitants contacted for the study was estimated to be representative of the 2969156 inhabitants living in Yaoundé, with a margin of error of $3 \%$ in the estimations. From the 1066 persons contacted, only 793 patients completed the questionnaire. Selection bias was assessed and is discussed. The inclusion criteria were as follows: age between 12 and 65 years; living for at least 


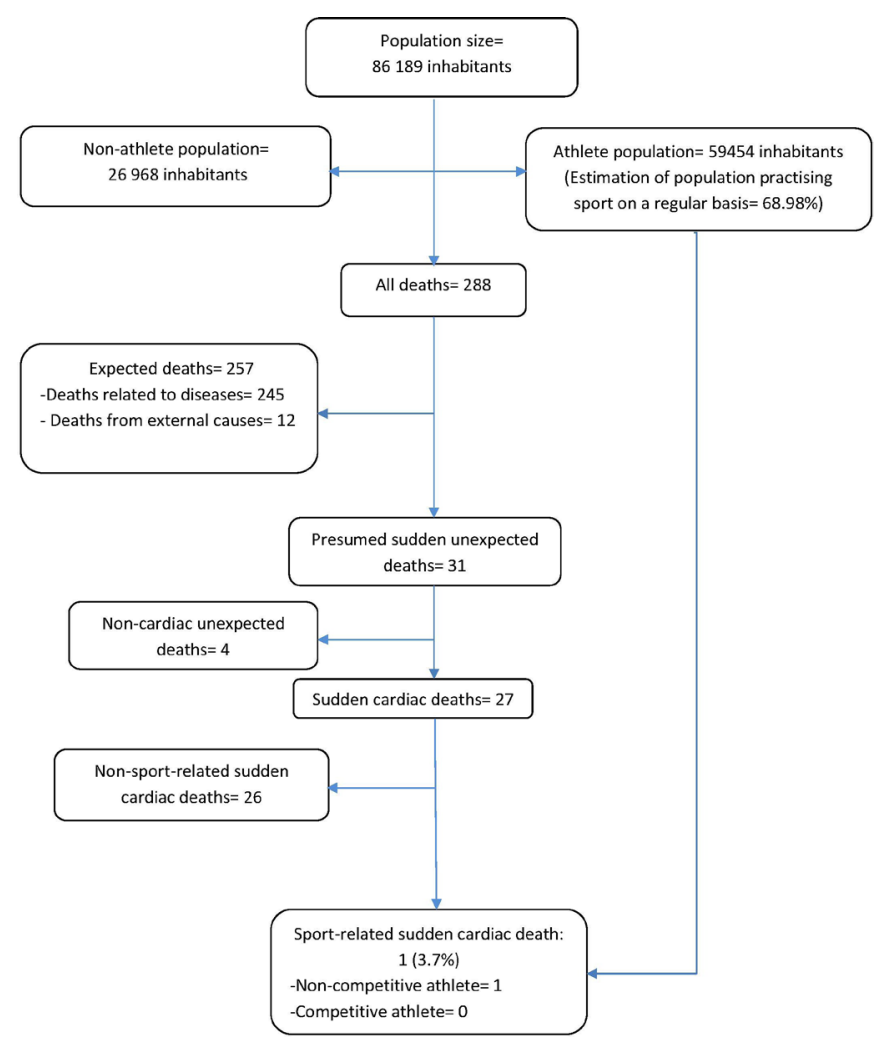

Figure 1 Flow chart of the study population.

6 months in the city; and no form of physical activity forbidden by a medical professional. Respondents were asked whether they engage in any physical activity for more than 3 hours per week.

Written informed consent was obtained from the legal representatives and family members of the victim. All participants of the sports-related survey provided consent before their information was collected.

\section{Statistical analysis}

The percentage of individuals from the Yaoundé population sample who performed regular physical activity of $\geq 3$ hours per week (non-competitive athletes) was determined. Mean and SD were used to summarise continuous variables, while number and percentage were used for categorical variables. Comparisons between those who participated in non-competitive athletes enduring $\geq 3$ hours per week of physical activity compared with $<3$ hours of physical activity per week were done using t-test for continuous variables and $\chi^{2}$ test for categorical variables.

To determine the incidence of SrSCA in the general population, the percentage of non-competitive athletes derived from the cross-sectional survey of the Yaoundé general population sample was applied to the Douala population, where data on the incidence $(95 \%$ CI) of SCA were collected, to obtain the number of noncompetitive athletes in this population. Then from the number of SrSCA cases identified from the Douala population, the incidence per 100000 athletes-years and 95\% CI were computed.
All analyses were performed using SAS (V.9.3) software, and the statistical significance threshold was set at 0.05 .

\section{Patient and public involvement}

Patients and/or the public were not involved in the design, or conduct, or reporting, or dissemination plans of this research.

\section{RESULTS}

Overall, 793 out of 1166 persons were surveyed during the cross-sectional study. The average age of participants was $27.3 \pm 10.7$, most of them were men $(56.2 \%)$. More than two-thirds $(69.0 \%)$ of participants out of the 793 surveyed declared engaging in physical activity (table 1). There was an association between schooling and engaging in physical activity; $51.2 \%$ of people engaging in physical activity were students and $26.4 \%$ of students were categorised as non-active $(\mathrm{p}=0.0007)$.

Based on the results obtained from the 12-month extended multisource surveillance of the Douala SCD registry, ${ }^{6} 27(9.4 \%)$ deaths were presumed to be of cardiac origin (table 2). The age-adjusted incidence of SCA in the general population (based on African age structure) was 33.6 (95\% CI 22.2 to 44.9) cases per 100000 persons per year. A 35-year-old non-competitive female athlete died while running. Given the prevalence of recreational sport athletes of $69.0 \%$, there was one sports-related cardiac arrest in this population out of 59452 athletes per year, representing 1.7 (95\% CI 0.2 to 12.0 ) cases per 100000 athletes per year (table 2 ).

The associated cardiovascular diseases among SCA victims were hypertension $(22.2 \%)$, diabetes $(11.1 \%)$, heart failure $(14.8 \%)$, dilated cardiomyopathy $(7.4 \%)$ and myocardial infarction (7.4\%). In-hospital cardiac arrest occurred in $37.0 \%$ of cases, $55.6 \%$ at home, $3.7 \%$ at work and $3.7 \%$ in public place. Death occurred while victim was asleep in $11.1 \%$ of cases, $85.2 \%$ while resting and $3.7 \%$ were sports-related.

\section{DISCUSSION}

\section{Estimates of SCA in general populations of African athletes}

In the Oregon SCD registry, $63(5 \%)$ of the 1247 SCA cases occurred during sports activities, yielding an incidence of 2.2 (95\% CI 0.8 to 3.5) per 100000 athletes per year. The same study reported 55.5 (95\% CI 54.1 to 56.8 ) cases per 100000 persons per year in the general population, ${ }^{16}$ representing a 25-fold higher frequency of death compared with that of athletes. In the nationwide Danish survey, the incidence was 3.0 (95\% CI 2.0 to 4.3 ) in noncompetitive athletes aged 36-49 years, whereas the rate in the general population was 10.7 (95\% CI 10.0 to 11.5 ) per 100000 persons per year, ${ }^{17}$ which is almost a fourfold higher incidence. Although the denominator and numerator of our study came from different populations, the populations of Douala and Yaoundé are homogeneous, so the rates are reliable. The age-adjusted incidence of SCA among the general population of 33.6 (95\% CI 22.2 to 44.9 ) cases per 100000 persons per year ${ }^{14}$ is almost 
Table 1 Sociodemographic characteristics of participants of the Yaoundé survey

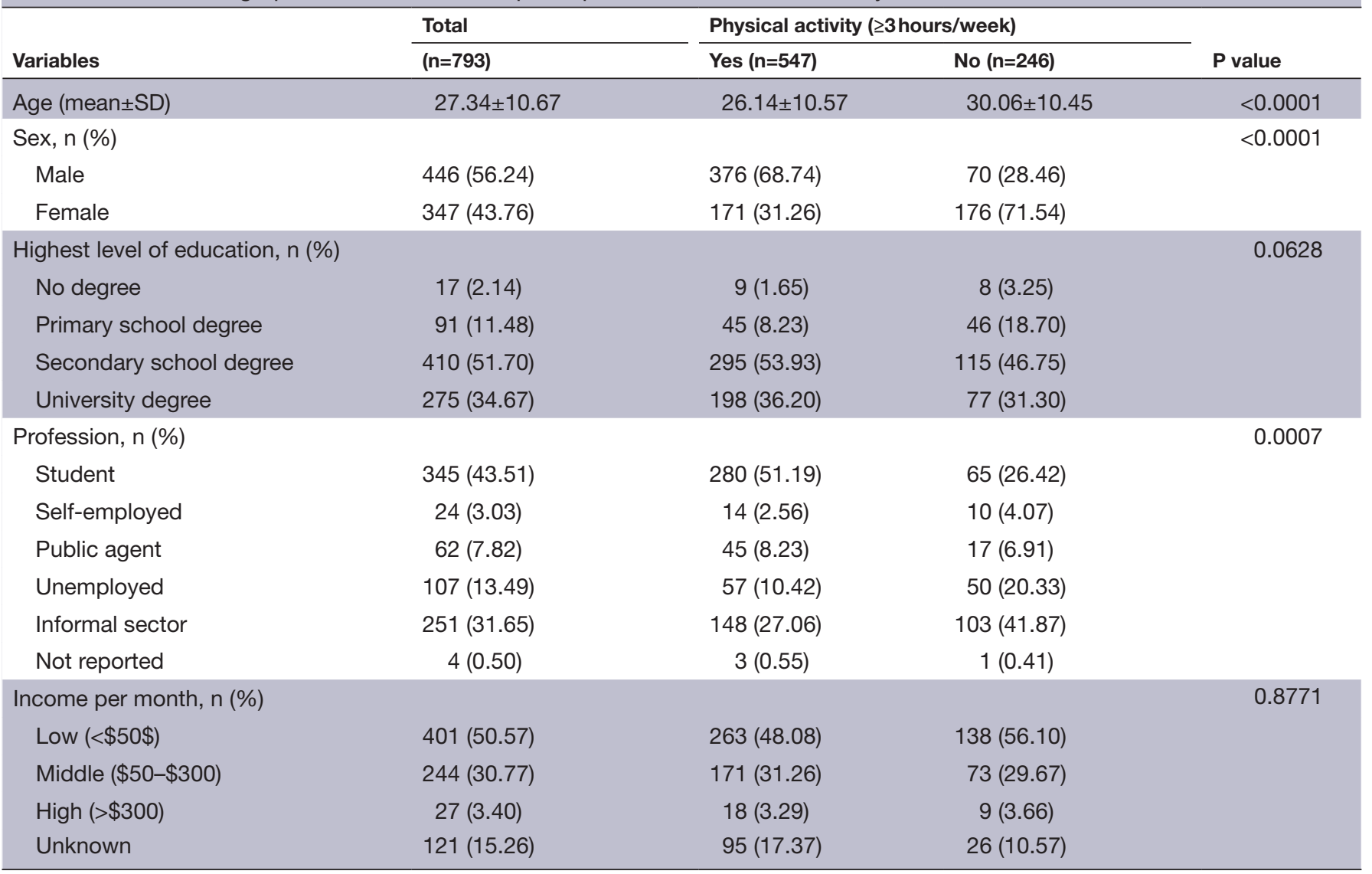

20-fold higher than the rate in athletes: 1.7 (95\% CI 0.2 to 12.0) per 100000 athletes per year. Hence, the burden of SrSCA in this general urban population from Africa is comparable with that in the Oregon registry.

\section{Challenging identification of cases and causes}

Several factors affect case identification, including the definition of what an athlete is, methods of data acquisition, lack of mandatory reporting requirements in most settings, inclusion or exclusion of cases based on time and location of the event, inclusion of all cardiac events (including survivors) versus only those resulting in death, and the population examined. The selection and calculation of the denominator also vary widely in precision. These limitations are greater in African settings for several reasons: (1) poor documentation of medical history of athletes, (2) lack of sport clinics, (3) lack of diagnostic work-up such as coronary angiography laboratory, cardiac MRI, electrophysiological equipment and postmortem molecular techniques, and (4) a very low rate of autopsied cases owing to cultural and financial barriers as well as lack of experienced forensic scientists. ${ }^{18}{ }^{19}$ Consequently, survivors are rare, with limited access to full personal and family diagnostic work-up, and deceased athletes rarely undergo retrospective medical examination.

In the Douala population where SCD was initially assessed, the cases were defined from verbal autopsies and EMS records. ${ }^{14}$ Definitive causes of death were not available in all cases given the low levels of cardiovascular work-up investigations and actual postmortem

Table 2 Crude incidence of sudden cardiac arrest based on the two studies

\begin{tabular}{llllc}
\hline Characteristics & General population & & & \\
\hline Population size & Total $(n=86189)$ & Men $(n=42664)$ & Women $(n=43525)$ & Athletes* $(n=59452)$ \\
Sudden cardiac death (SCA) & 27 & 14 & 13 & 1 \\
Median age (interval interquartile) & $46(37)$ & $56(42)$ & $35(16)$ & $35(-)$ \\
SCA incidence (per 100000 person-years) & $31.3(20.3-41.3)$ & $32.8(19.2-40.6)$ & $29.9(21.6-44.6)$ & - \\
SrSCA incidence (per 100000 athletes-years) & - & - & - & $1.7(0.2-12.0)$ \\
\hline
\end{tabular}

*The denominator of the study population was taken from the cross-sectional survey of the Yaoundé survey.

SCA, sudden cardiac arrest; SrSCA, sports-related sudden cardiac arrest. 
examinations performed by pathologists. Nevertheless, there are compelling data suggesting that HCM is more prevalent in people of African descent when compared with whites ${ }^{20}$ and is the most frequent cause of SrSCA in people of African origin. ${ }^{21}$ Indeed, African-American athletes have shown a higher rate of HCM than other ethnic groups. ${ }^{22}$ In the US National Registry of Sudden Death in Athletes study published more than 15 years ago, and which documented more than 2400 deaths in athletes between the ages of 13 and 25, Maron et $l^{7}$ showed that more than one-third (36\%) of reported cardiovascular deaths were caused by HCM and that more than $50 \%$ of them occurred in young, male black athletes. ${ }^{6}$ Most recent contemporary national data from the USA depicted that young college competitive black athletes were three times more likely to suffer SrSCA compared with their white counterparts. In that study, black athletes were more likely to die of a cardiomyopathy (HCM and dilated cardiomyopathy) than white athletes, although most of the cases of SrSCA in the entire study population were autopsy-negative sudden unexplained deaths (25\%), with HCM accounting for only $8 \% .^{6}$ The relative reduction in proportion of HCM-related SrSCA in recent times might be accounted for by increased preparticipation screening. ${ }^{2123}$ In the Tunisian registry of sudden deaths during sports activity, Allouche $e t a l^{24}$ autopsied 32 cases. HCM was the predominant aetiology, with a prevalence of $41 \%$ in young patients $<35$ years old. ${ }^{7}$

\section{Prevention and perspectives}

The prevention of SCA during competitive and noncompetitive sports has been extensively discussed in the literature. Most consensus recommendations call for a screening protocol with the subject's personal history, family history and physical examination. ${ }^{23}$ Screening in the European guidelines includes a 12-lead ECG to identify athletes with previously undiagnosed heart disease, ${ }^{23}$ while the American Heart Association/American College of Cardiology guidelines do not recommend universal ECG screening. ${ }^{256}$ Italian investigators reported a nearly 90\% decline in the annual incidence of sudden cardiovascular death in competitive athletes in the Veneto region of northeastern Italy. ${ }^{27}$ This change in death rate occurred in parallel with progressive implementation of nationwide screening and the increasing identification of affected athletes, who were then disqualified from competitive sports. Indeed, the ECG is abnormal in up to $95 \%$ of patients with HCM. $^{28}$

ECG screening is not systematically performed in many African countries for several reasons. First, ECG machines are not available in many medical centres. Second, the cost of examination is relatively higher compared with the minimum wage. For example, an ECG examination in France costs less than $€ 15$ compared with $€ 20$ and $€ 30$ in low-income countries such as Cameroon and Gabon, respectively. Third, Africa has an insufficient number of physicians qualified in sports medicine and who are able to accurately interpret an athlete's ECG.
Fourth, specialised sports medicine clinics are few and far between. As a result, African athletes have less access to medical care, so it is less likely that young black men will receive a diagnosis of $\mathrm{HCM}^{29}$ Consequently, African athletes with HCM are also less likely to be disqualified from competition to reduce their risk of sudden death, in accordance with the recommendations of the Bethesda Conference. ${ }^{29}$

The real burden of cardiac death in both competitive and non-competitive African athletes needs to be established. Prospective cohort registries should therefore be set up. Identifying athletes at risk through mandatory preparticipation ECG screening and training courses on cardiopulmonary resuscitation, including the use of automated external cardioverter-defibrillators, for every single athlete should be part of public health policies. The African Heart Rhythm Association, which is part of the Pan-African Society of Cardiology, has adopted this agenda as its roadmap for reducing cardiac arrest and death during exercise on the African continent. ${ }^{30} 31$

\section{Study strengths and limitations}

To our knowledge, this study represents the first comprehensive prospective assessment of the incidence of SCA in athletes in sub-Saharan Africa. In addition, the data sources are exhaustive. Furthermore, no index death was lost, thanks to the use of the public health network with health workers playing an important part in data collection. Nevertheless, the study has several weaknesses. First, it was conducted with limited financial support and had to be stopped prematurely after 12 months instead of running the full 3 years initially planned. Second, the expected number of 1066 participants was not attained, which could lead to selection bias. Third, the lack of information about non-respondents did not allow any sensitivity analyses. However, the study team did not identify any evidence showing that non-respondents engaged in physical activity regularly. Therefore, confidence on the incidence estimates should be regarded as quite low.

\section{CONCLUSION}

The rate of cardiac arrest during sports in this general African population seems to be comparable with that of Western populations. Larger cohort studies to establish a more accurate burden of cardiac arrest in African athletes are warranted. The availability of these data will help to fuel adequate prevention policies in sub-Saharan countries.

Acknowledgements The study team expresses deep gratitude to all the participants who consented to fill in the questionnaire, and especially to all victims' family members who agreed to provide us information regardless of their sadness. Thank you to Julienne-Louise Ngo Likeng for mentoring the fellows conducting the cross-sectional study survey. Thank you to Mr Ray Cooke for editorial assistance with the manuscript.

Contributors GMKT was responsible for data collection and contributed to the creation of the first manuscript draft. MN was responsible for analysing the data collected and participated in the conception of the study and in the preparation of the manuscript. SM oversaw the coordination of data collection in Cameroon and participated in drafting the manuscript. SCTT was co-responsible for data 
collection and contributed to the creation of the first manuscript draft. AS, OAA and MFY participated in data interpretation and contributed to the creation of the manuscript. $A B$ is the study's principal investigator who designed the study and coordinated the manuscript. All authors approved the final version of the manuscript and agree to be accountable for all aspects of the work in ensuring that questions related to the accuracy or integrity of any part of the work are appropriately investigated and resolved.

Funding The authors have not declared a specific grant for this research from any funding agency in the public, commercial or not-for-profit sectors.

Competing interests None declared.

Patient consent for publication Not required.

Ethics approval Approval from the National Ethics Committee and the regional delegation of the Ministry of Public Health was obtained before starting the survey. This study received agreement with the local and administrative ethical committee in Cameroon and the ethical approval letter has been delivered (number: 2018/0592/CEIRSH/ESS/MSP)

Provenance and peer review Not commissioned; externally peer reviewed.

Data availability statement Data are available upon reasonable request. All free texts entered below will be published.

Open access This is an open access article distributed in accordance with the Creative Commons Attribution Non Commercial (CC BY-NC 4.0) license, which permits others to distribute, remix, adapt, build upon this work non-commercially, and license their derivative works on different terms, provided the original work is properly cited, appropriate credit is given, any changes made indicated, and the use is non-commercial. See: http://creativecommons.org/licenses/by-nc/4.0/.

ORCID iD

Aimé Bonny http://orcid.org/0000-0002-3666-4234

\section{REFERENCES}

1 Paratz ED, Rowsell L, Zentner D, et al. Cardiac arrest and sudden cardiac death registries: a systematic review of global coverage. Open Heart 2020;7:e001195.

2 Wong CX, Brown A, Lau DH, et al. Epidemiology of sudden cardiac death: global and regional perspectives. Heart Lung Circ 2019;28:6-14.

3 Harmon KG, Drezner JA, Wilson MG, et al. Incidence of sudden cardiac death in athletes: a state-of-the-art review. Heart 2014;100:1227-34.

4 Mohananey D, Masri A, Desai RM, et al. Global incidence of sportsrelated sudden cardiac death. J Am Coll Cardiol 2017;69:2672-3.

5 Ahmed HB, Allouche M, Zoghlami B. Mort subite d'origine cardiaque au nord de la Tunisie: variation circadienne hebdomadaire et saisonnière, 2014. Available: https://www.em-consulte.com/en/ article/888195 [Accessed 02 Jun 2019].

6 Harmon KG, Asif IM, Maleszewski JJ, et al. Incidence, cause, and comparative frequency of sudden cardiac death in national collegiate athletic association athletes: a decade in review. Circulation 2015;132:10-19.

7 Maron BJ, Haas TS, Ahluwalia A, et al. Demographics and epidemiology of sudden deaths in young competitive athletes: from the United States national registry. Am J Med 2016;129:1170-7.

8 Fishman GI, Chugh SS, Dimarco JP, et al. Sudden cardiac death prediction and prevention: report from a national heart, lung, and blood Institute and heart rhythm Society workshop. Circulation 2010;122:2335-48.

9 McKinney J, Velghe J, Fee J, et al. Defining athletes and Exercisers. Am J Cardiol 2019;123:532-5.

10 World Health Organization. Global recommendations on physical activity for health, 2010. Available: http://whqlibdoc. who.int/ publications/2010/9789241599979_eng.pdf [Accessed 24 May 2020].

11 von Elm E, Altman DG, Egger M, et al. The strengthening the reporting of observational studies in epidemiology (STROBE) statement: guidelines for reporting observational studies. Lancet 2007;370:1453-7.
12 Bonny A, Noah DN, Ngantcha M, et al. Epidemiology of sudden cardiac death in Cameroon: rationale and design of the Douala-SUD survey. Arch Cardiovasc Dis 2014;107:433-42.

13 World Health Organization. ICD-10, 2016. Available: http://apps.who. int/classifications/icd10/browse/2016/en

14 Bonny A, Tibazarwa K, Mbouh S, et al. Epidemiology of sudden cardiac death in Cameroon: the first population-based cohort survey in sub-Saharan Africa. Int J Epidemiol 2017;46:1230-8.

15 Nichols EK, Byass P, Chandramohan D, et al. The WHO 2016 verbal autopsy instrument: an international standard suitable for automated analysis by InterVA, InSilicoVA, and tariff 2.0. PLoS Med 2018;15:e1002486

16 Marijon E, Uy-Evanado A, Reinier K, et al. Sudden cardiac arrest during sports activity in middle age. Circulation 2015;131:1384-91.

17 Risgaard B, Winkel BG, Jabbari R, et al. Sports-related sudden cardiac death in a competitive and a noncompetitive athlete population aged 12 to 49 years: data from an unselected nationwide study in Denmark. Heart Rhythm 2014;11:1673-81.

18 Talle MA, Bonny A, Scholtz W, et al. Status of cardiac arrhythmia services in Africa in 2018: a PASCAR sudden cardiac death Task force report. Cardiovasc J Afr 2018;29:115-21.

19 Bonny A, Ngantcha M, Scholtz W, et al. Cardiac arrhythmias in Africa: epidemiology, management challenges, and perspectives. $J$ Am Coll Cardiol 2019;73:100-9.

20 Sheikh N, Papadakis M, Panoulas VF, et al. Comparison of hypertrophic cardiomyopathy in Afro-Caribbean versus white patients in the UK. Heart 2016;102:1797-804.

21 Maron BJ, McKenna WJ, Danielson GK, et al. American College of Cardiology/European Society of cardiology clinical expert consensus document on hypertrophic cardiomyopathy. A report of the American College of cardiology Foundation Task force on clinical expert consensus documents and the European Society of cardiology Committee for practice guidelines. J Am Coll Cardiol 2003;42:1687-713

22 Maron BJ, Carney KP, Lever HM, et al. Relationship of race to sudden cardiac death in competitive athletes with hypertrophic cardiomyopathy. J Am Coll Cardiol 2003;41:974-80.

23 Corrado D, Pelliccia A, Bjørnstad HH, et al. Cardiovascular preparticipation screening of young competitive athletes for prevention of sudden death: proposal for a common European protocol. consensus statement of the study group of sport cardiology of the Working group of cardiac rehabilitation and exercise physiology and the Working group of myocardial and pericardial diseases of the European Society of cardiology. Eur Heart J 2005;26:516-24.

24 Allouche M, Boudriga N, Ahmed HB, et al. [Sudden death during sport activity in Tunisia: autopsy study in 32 cases]. Ann Cardiol Angeiol 2013;62:82-8.

25 Maron BJ, Levine BD, Washington RL, et al. Eligibility and disqualification recommendations for competitive athletes with cardiovascular abnormalities: task force 2: preparticipation screening for cardiovascular disease in competitive athletes: a scientific statement from the American heart association and American College of cardiology. J Am Coll Cardiol 2015;66:2356-61.

26 Baggish AL, Battle RW, Beckerman JG, et al. Sports cardiology: core curriculum for providing cardiovascular care to competitive athletes and highly active people. J Am Coll Cardiol 2017;70:1902-18.

27 Corrado D, Basso C, Pavei A, et al. Trends in sudden cardiovascular death in young competitive athletes after implementation of a preparticipation screening program. JAMA 2006;296:1593-601.

28 Piro M, Fioranelli M. Hypertrophic cardiomyopathy screening program in the athlete - second in series. ESC Council for Cardiology Practice, 2015.

29 Pelliccia A, Zipes DP, Maron BJ. Bethesda Conference \#36 and the European society of cardiology consensus recommendations revisited a comparison of U.S. and European criteria for eligibility and disqualification of competitive athletes with cardiovascular abnormalities. J Am Coll Cardiol 2008;52:1990-6.

30 Bonny A, Ngantcha M, Yuyun MF, et al. Cardiac arrhythmia services in Africa from 2011 to 2018: the second report from the pan African Society of cardiology working group on cardiac arrhythmias and pacing. Europace 2020;22:420-33.

31 Rwebembera J, Jeilan M, Ajijola OA, et al. Cardiac pacing training in Africa: endorsed by the Africa heart rhythm association (AFHRA): JACC international. J Am Coll Cardiol 2020;76:465-72. 